\title{
Modeling and Simulation of PV Panel under Different Internal and Environmental Conditions with Non-Constant Load
}

\author{
M. R. Rashel ${ }^{1,2,4}$, R. Melicio ${ }^{1,2,3}$, M. Tlemcani ${ }^{1,2}$, T. Goncalves ${ }^{1}$ \\ ${ }^{1}$ Universidade de Évora, Évora, Portugal, ruimelicio@gmail.pt \\ ${ }^{2}$ Instituto de Ciências da Terra, Universidade de Évora, Portugal \\ ${ }^{3}$ IDMEC, Instituto Superior Técnico, Universidade de Lisboa, Lisbon, Portugal \\ ${ }^{4}$ Department of Computer Science and Engineering, Daffodil International \\ University, Dhaka, Bangladesh
}

\begin{abstract}
This paper focuses on PV power conversion under different internal and environmental conditions with non-constant load, connected to a smart grid system. Due to environmental conditions, the PV system is a non-linear system and difficult to predict the power conversion. In the aspect of internal variables, it includes the five parameters of the single diode solar cell model identify their sensitivity through error function. It also identifies the relation between environmental conditions, mainly: irradiance, temperature and wind speed. The modeling and computational simulation with laboratory work identify the effects of internal and environmental effect on the system. The model gives details about the sensitivity of each environmental condition using error function. The work includes the decrease of energy conversion by the solar panel as a function of time due to the shadow effect that affects its performance. Besides these, a smart system is introduced as a DAQ system in laboratory environment to get in real time the power conversion value with the P-V and I-V characteristics of the PV panel.
\end{abstract}

Keywords: Internal and Environmental Variables, Solar Panels, Error function, Shadow effect, DAQ system.

\section{Introduction}

Due to increasing dependency on electric equipment requirement of electric energy also increases. For fulfilling the requirement, the energy supply sector is searching for source of energy. Renewable energy is a solution which ensures clean environment. Photovoltaics is one of the renewable energy source that get attention of the researchers, business men and policy makers. PV got the attention because of its simple mechanism and low cost production in last 10 years. Its behavior is random, depends on environment parameters [1], [2], [3]. It has great potential to supply electricity without producing $\mathrm{CO}_{2}$ emissions in its working life cycle. PV reached up to $22.2 \%$ efficiency [4] and it has to go a long way to improve its efficiency and performance. Due to different internal and external facts, it could not give the best performance when working in the active ground. There are different ways to improve the power generation 
rate of it and among them: 1) improvement of surrounding condition (remove dust, remove obstacles that decrease the performance); 2) optimum parameter value identification; 3) include the ambient temperature with the value of wind speed. These important facts have great impact on it. These are most important to get the best out of a solar PV plant. For estimating the plant value need these type of sophisticated calculation which is shown in this work. This work calculated the PV power generation more approximately than before and helped the smart grid (SG) system to estimate the power generation more accurately [1].

The solar irradiation is differed from place to place on the earth surface. But the source of solar energy is continuous and abundant in nature and in no need of refueling. But the intensity of the solar irradiation is varying place to place. The average distribution of solar radiation through the earth surface [5] is shown in Fig. 1.

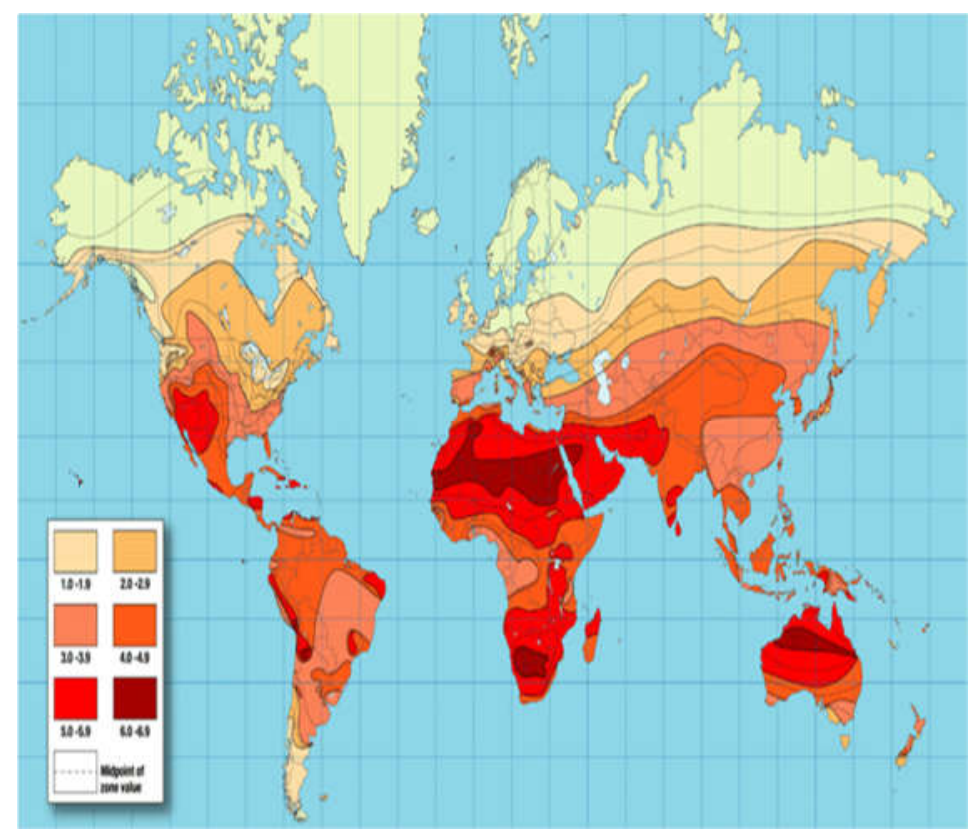

Fig. 1. Average distribution of solar radiation through the Earth surface [5].

In Fig. 1 on the earth surface, there are six zone, which is based on the average amount of solar irradiation in a year on an area of $1 \mathrm{~m}^{2}(\mathrm{~kJ})$ [6]. There are some places that have huge amount of solar irradiation all over the year and could generate huge amount of energy from solar power; Portugal is one of the places in Europe which gets one of the maximum amount of solar radiation. This place is impeccable to produce vast amount of electricity and heat from solar radiation; Portugal's industries are giving focus on this source of energy and huge investment is arranged to get more out of this. For making a smart grid system including the nano and macro grid solar plant with central grid, needs improvement to increase the efficiency of PV system. 


\section{Relationship to Industrial and Service Systems}

The 18th century industrial revolution, said to be the First Industrial Revolution, brought into force the historically never seen before paradigm of industrialization and urban society. Subsequent research and development have delivered scientific evolution triggering technological innovation for industrial and service systems with significant impact into the society. After an industrial revolution, a new set of technological innovation with significant impact into the society, i.e., expressively changing the society, is categorized as a consequent born age said to be the following industrial revolution. In now-a-days a view of a new set of technological innovation for industrial and service systems points into what is said to be the paradigm of a fourth industrial revolution, i.e., Industry 4.0 [7]. Industry 4.0 indorses the interconnection of physical items such as sensors, devices and enterprise assets, interfacing with one each other directly or by the Internet [7], [8], allowing Cyber-Physical Systems (CPS) processes. The main characteristics of these processes are decentralization and autonomous behavior [7]. A PV power system is in the new set of innovation in the scope of a CPS interfaced with information systems with real-time digital platform services. This PV system must be interfaced with urban infrastructures, allowing capabilities of smart grids to schedule the batteries in an environment of smart cities [9]. Demand side involvement in a power system is a functionality link with smart grids that is connected with PV power conversion system. The communication and computation requirements adopted by PV system user aggregator must include advanced metering infrastructure (AMI), bi-directional data communication using cellular communications and other wireless communication technology including internet of things (IoT), supervisory control and data acquisition (SCADA) [10]. Technological innovation software for the PV aggregator is needed for taking full advantage of it, persuading customer for benefits of being with an PV aggregator and consequently favoring the desired rise on the PV power generation market penetration [9]. This work is for increasing the efficiency of the PV system that is integrated with central smart grid system. Due to lack of maintenance and lack of knowledge, systems do not get the best performance. It needs deep analysis, both internal and external parameter that is accomplished through this research work. The work is consisting of four different parts. First part works with internal and external parameters sensitivity identification through error function to identify the optimal value identification point to get optimal value for the system to help PV panel to get optimal solution. For external variables like irradiance, ambient temperature and wind speed's get their sensitivity to the PV panel and how the effect the output of PV is identified. The effect of environmental parameters is shown graphically that introduce new equation which includes wind speed importance for getting more accurate approximate value of power generation, what makes the central grid smarter. In author part DAQ system is used to evaluate a PV panels output with different resistance to get the effect of non-constant load to the system. This work show different behavior that help to get idea of non-constant load over PV, also important for the energy service system. At the last part, the obstacles effect on PV panel is identified. Obstacles like shadow over panel's surface make PV more unstable in the sense of power production. It is important to identify this types of effect causes to get the idea of fault in the system it could be permanent or temporary. Identification of faults type is important to give the solution for the problem. One of the important identification is the 
characteristics of obstacles are categorized in two parts. This identification, could integrated with service system of PV [1].

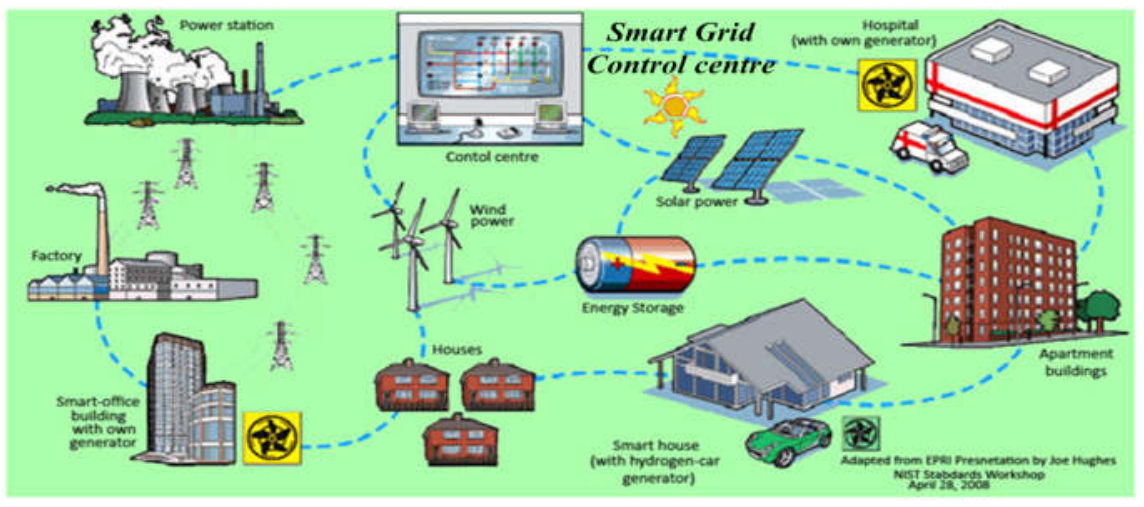

Fig. 2. Smart grid with renewable energy system [2].

This work knowledge is important to connect PV nano, micro grid system with center grid system; it has significant value in the sector of power industry. Accurate estimation of power from the small systems help the central grid to estimate the other energy source for generated desirable production.

\section{State of the Art}

In the year of 2015 a historical decision had been taken in the Paris Climate Conference [11] to limit the global warming and help to protect the environment. In that conference 195 countries from all over the world agree in a decision to limit the carbon emission using available technology and science. Renewable energy sources and technologies have a great role in this decision and world is looking for developing a system that will help to build sustainable environment.

In [12] describes that it is not possible to make a risk free energy resource. In this work it suggests that to choose a source of energy, the priority should give to environmental effects and the cost issues. In this both section, renewable energy is the best solution. In [13], [14] state about renewable energy for sustainable development. Renewable energy sources named solar, biomass, geothermal or wind are analyzed from both environmental and economical view point. In [15] describes a detail overview about integrating renewable energy with central smart grid system. PV power conversion is not linear in nature and for connecting, them with SG need more improvement computational tools, smart devices.

In [16], [17] give details about the modeling and simulation for integrating wind farm and solar plant with the smart grid. The simulation model was developed in the Matlab/Simulink. It also gives details about nano grid with a smart house system with solar panels. It states that good prediction model is important for SG. In [18-23] states about different approaches to integrate PV system with SG. These works discuss about 
control methods and about DC-DC boost converter and two-level converter. And also define three level inverter. In [22] states the way how to integrate the poly-Si PV system with the central grid. This work introduces a fuzzy controller to control the converter and show the efficient way to connect with SG. In [24], [25] states different methods to get I-V and P-V characteristics from five parameters single diode PV model those are based on the datasheet values. These works include different test conditions under changing irradiation and temperature with those conditions PV power production. In [26] describes a five parameters model that included photocurrent, dark saturation current, series resistance, shunt resistance and diode ideality factor. Using datasheet values this model is created as like [25]. Under real environmental conditions the model is tested and verified.

In [27] states the effect of wind speed on PV panels' power generation. It analysis the correlation between tilt angles and wind speed to get the maximum power generation angle in different season.

In [28] states and shows that the operating temperature of PV is an important variable that affect the maximum power generation from the PV. In this work it is stated that temperature has linear relation with PV power generation rate. In [29] states the effect of ambient temperature and wind speed about the performance of monocrystalline PV power conversion. In [30] states the enhanced condition for PV under varying environmental condition. Under varying environmental condition, load is also changing depending on it. In warm or cold condition, the use of different electronic devices to varying the temperature and the load also increase. This work show that load analysis is an important fact to make an optimum PV power conversion system.

In [31] describes and gives details about different dust condition in Libya on PV power conversion performance. It gives the comparison between PV power conversion performance under dust and clean environment. It shows that the dust on PV surface losses the power conversion performance. In [32] describe a simulator that can simulate the PV power conversion system under partial and dynamic shadow condition. In [33] states the dust effect on PV modules' surface. It shows the relation between dust deposition on PV surface and in that condition the sunlight way out to its surface.

After going through all these state of the art, it is important to get more accurate PV five parameter model that also should include wind speed effect in the equation. Load analysis is important and need more analysis with real time scenario. Shadow effect is important to take account to identify different loss from PV power conversion system. All these problem are analyzed and identified valuable result that help to make better approximate model that give better prediction result for PV power conversion system.

\section{Research Contribution and Innovation}

Four different analysis had done and generate knowledge for the PV power generation system to improve its performance in real working field. This information is important to integrate it with smart grid and also identify fault in PV plant.

Single diode five parameters PV model is used to analysis different internal and external parameters with error function. Fig. 2 is the equivalent circuit diagram for the PV cell model. 


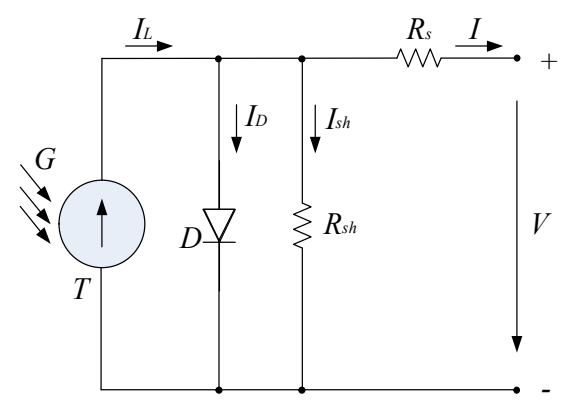

Fig. 3. Single diode five parameters PV cell model.

In Fig. 3. $I_{L}$ is the photocurrent which is the current source for the circuit, single diode $D$ which have $I_{D}$ current across it, a series resistance $R_{S}$ which represents the resistance in the cell, shunt resistance $R_{s h}$ is in parallel [1]. The I-V characteristic is formulated by an implicitly function is given by:

$$
I=I_{L}-I_{D}-I_{S h}=I_{L}-I_{0}\left\{\exp \left[\left(\frac{q\left(V+I R_{S}\right)}{n k T}\right)\right]-1\right\}-\left(\frac{V+I R_{S}}{R_{s h}}\right)
$$

In (1) $I_{L}$ is the photocurrent, $I_{D}$ is diode current, and $I_{0}$ is the dark saturation current, $R_{s}$ is the internal series resistance, $R_{s h}$ is the shunt resistance, $n$ is the diode ideality factor, $q$ is the electron charge, $k$ is the Boltzmann's constant, $T$ is the cell temperature of the junction [1]. The data for the c-Si PV cell at STC is shown in Table 1 [1].

Table 1. Data for the c-Si PV cell at STC [1]

\begin{tabular}{cccccl}
\hline Technology & $V_{m}$ & $I_{m}$ & $V_{o c}$ & $I_{s c}$ & $\infty_{s c}$ \\
\hline $\mathrm{c}-\mathrm{Si}$ & $0.55 \mathrm{~V}$ & $1.98 \mathrm{~A}$ & $0.64 \mathrm{~V}$ & $2.1 \mathrm{~A}$ & $1.7 \mathrm{~mA} /{ }^{\circ} \mathrm{C}$ \\
& & & & & \\
\hline
\end{tabular}

In Table 1 the values are used to do the simulation under different internal and environmental conditions. $I_{s c}$ is the value for short circuit current, $V_{o c}$ is the open circuit voltage, and $V_{m p}$ is voltage at maximum power point, $I_{m p}$ is the current at maximum power [1].

For understanding, different internal and external parameters' effect to the PV power conversion is identified using the sensitivity test and that is using error function. For each parameter error function gives detailed output, how it is sensitive to total system. It also assists to get approximate value of the starting point to find an optimum value for that parameter. The error function is given by:

$$
E(P)_{1 \ldots . . \mathrm{n}}=\frac{1}{n} \sqrt{\sum_{i=1}^{n}\left(I_{i P}-I_{i M}\right)^{2}}
$$

Single parameter with its error function [2], [34], [35] is shown in Fig 4. 


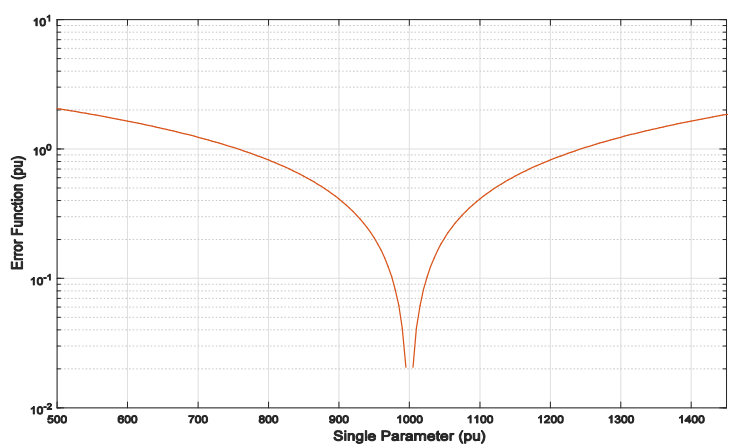

Fig. 4. Single parameter with error function.

Considering (2) the error function is calculated for each internal and external environmental parameter. After getting the values it builds a parameter vs error function graph like Fig. 3 and it gives the idea about the sensitivity [1]. The circuit diagram for the measurement system is shown in Fig. 5.

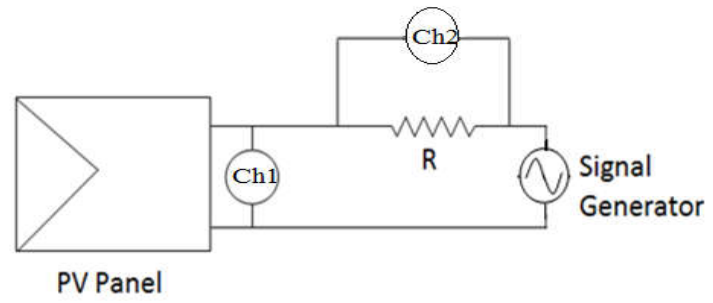

Fig. 5. Circuit diagram for the measurement system.

In Fig. 5 the DAQ system, channel 1 (Ch1) and channel $2(\mathrm{Ch} 2)$ is connected with work station through USB cable and also with measurement system. GPIB cable is used to connect the work station with the signal generator. The measurement process is as, at the starting, measurement is done to get the open circuit voltage using Ch1 and in that time the signal generator is disabled. After the measured value is passed to the workstation. This value is used to calculate the offset value and amplitude value for generating the RAMP signal. These values are send to the signal generator to generate accepted signals to initialize the measurement process, after it generates RAMP signal as commanded one. After this, the voltage is measured by $\mathrm{Ch} 2$. The current is calculated by the value of additive resistance $R$ and this measured voltages in different points. In this measurement process $10 \mathrm{~Hz}$ frequency is used for the signal. All these values are used to generate the I-V and P-V curves for the specific PV panel [1]. The Signal generator and DAQ connects with workstation is shown in Fig. 6. 


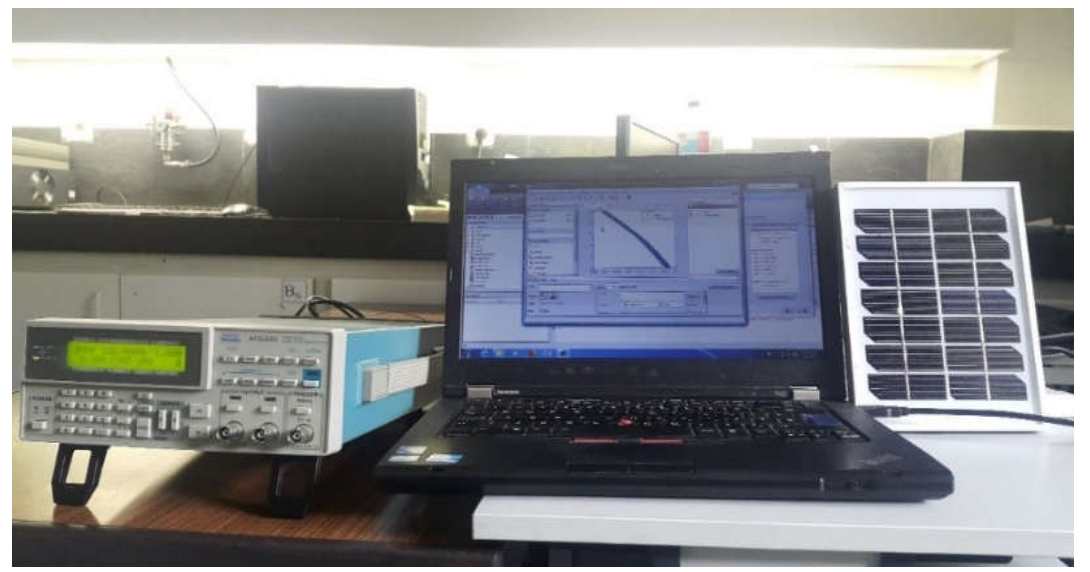

Fig. 6. Signal generator and DAQ connects with workstation.

For analyzing the obstacles over the PV panel or fault in PV panel the simulation is done in this work and Simulink model is used to build the model. The model gives the value like real time scenario [1]. The Matlab/Simulink model for understanding different obstacles over PV panel is shown in Fig. 7.

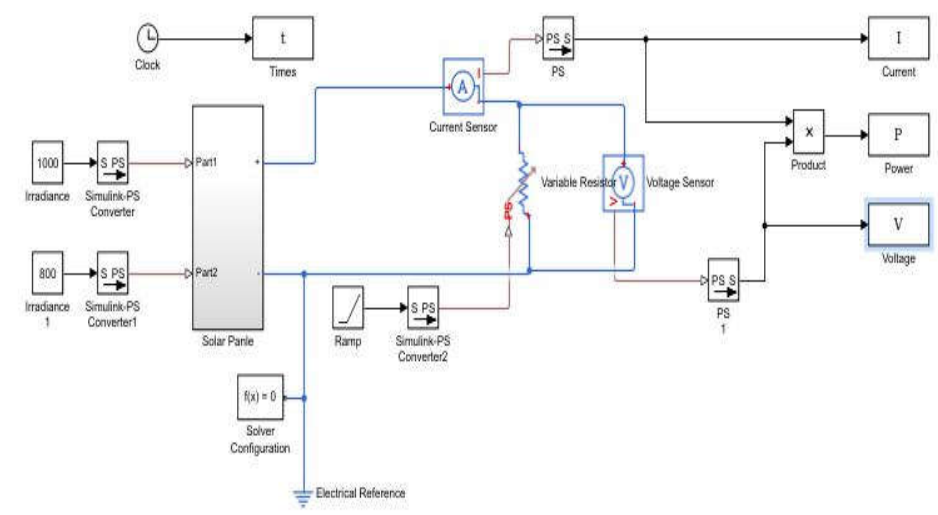

Fig. 7. Simulink model for understanding different obstacles over PV panel.

\section{Result and Discussion}

In this section, the result from four case studies are discussed. All these case studies are related to advance the quality of the PV power conversion that is connected with smart grid for better distribution. 


\subsection{Case study 1}

In this case study the sensitivity analysis for the internal and external parameters are analyzed through error function. Internal six parameters are analyzed through error function and those parameters are: photocurrent, cell temperature, diode ideality factor, series resistance, shunt resistance and diode saturation current.

Fig. 8 shows the six internal parameters named as a); the photocurrent as b); the cell temperature as c); the diode ideality factor as d); the series resistance as e); the shunt resistance as f); diode saturation current.

All of the above curves show minimum points where the error becomes zero, there the best values are achieved by minimizing the error among measured values and optimal value. Photocurrent, cell temperature, saturation current and diode ideality factor and series resistance are important parameters that show significant sensitiveness and on the other hand shunt resistance shows less sensitivity.
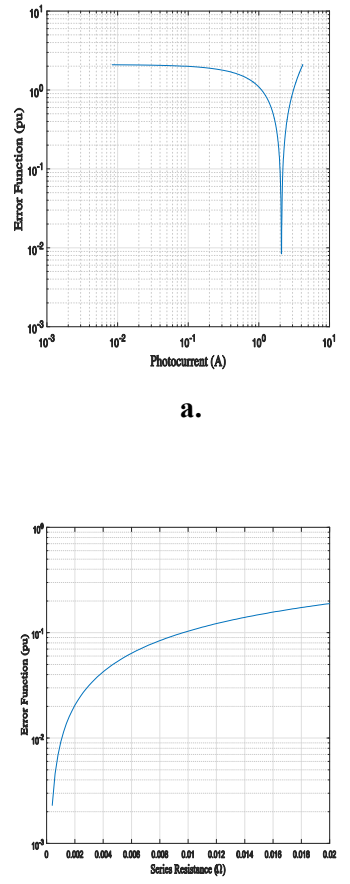

d.

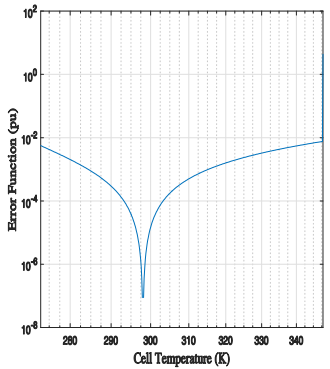

b.

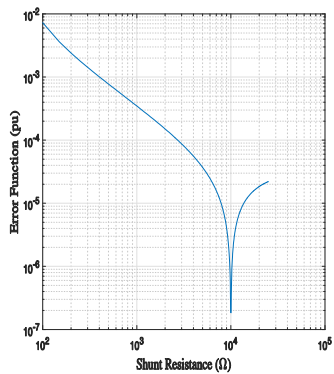

e.
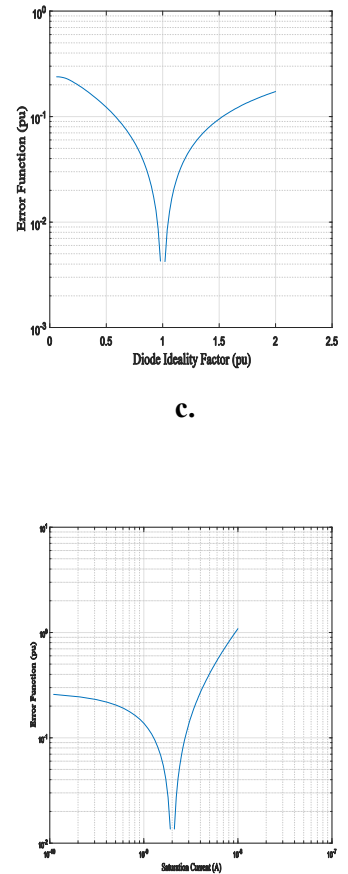

f.

Fig. 8. Six internal parameters named as a. photocurrent; b. Cell temperature; c. Diode ideality factor; d. Series resistance; e. Shunt resistance; f. Diode saturation current, all of them with error function. 


\subsection{Case study 2}

In this case study environmental variables are important and they have direct and indirect relationship with PV power conversion rate. Fig. 9 shows the changing value of irradiance as a); the change of PV power, b. increasing Irradiance increase the maximum power generation. This changing is happened nearly linear way. Fig. 10 shows the changing ambient temperature as a); the change of PV power conversion, b); increasing ambient temperature decrease maximum power generation and it's also decreasing in linear fashion. For wind speed, the changing value of wind speed make change the value of PV power conversion shown in Fig. 11. shows the changing wind speed as a); the change of PV power conversion, b); increasing wind speed increase the power generation.

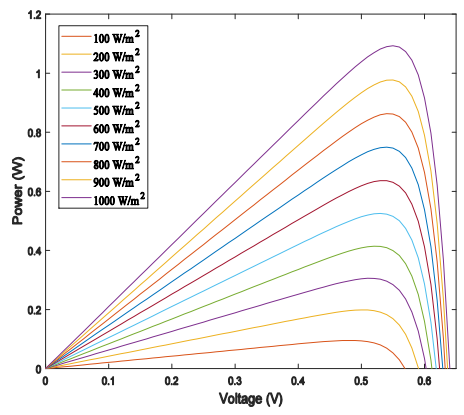

a.

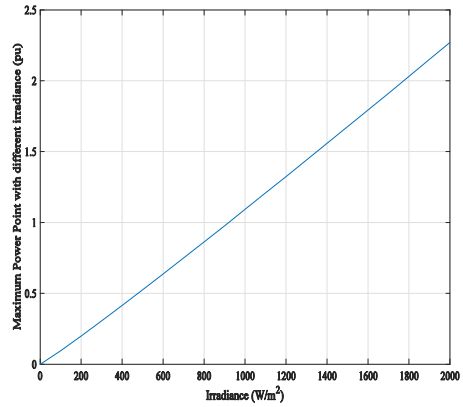

b.

Fig. 9. a. Changing value of Irradiance changes the value of PV power conversion; $b$. increasing Irradiance increase the maximum power point almost linearly.

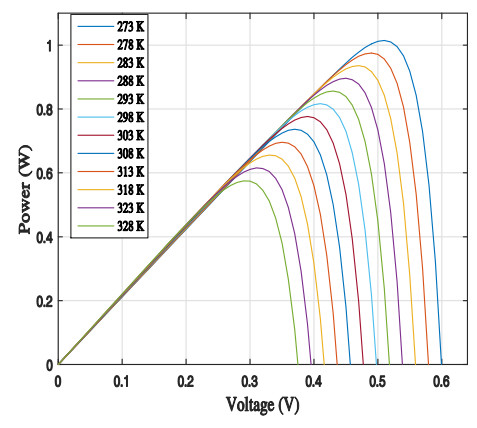

a.

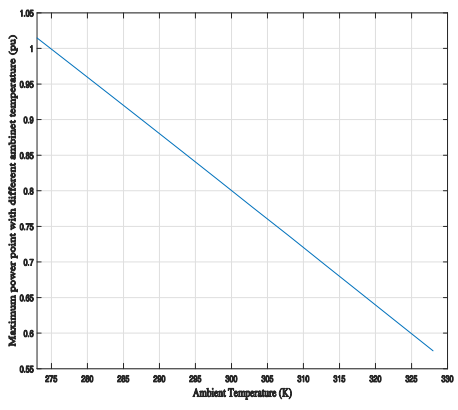

b.

Fig. 10. a. Changing value of ambient temperature changes the value of PV power conversion rate; $b$. increasing ambient temperature decrease the maximum power point linearly. 


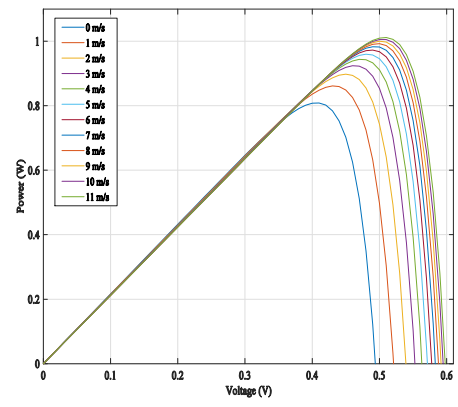

a.

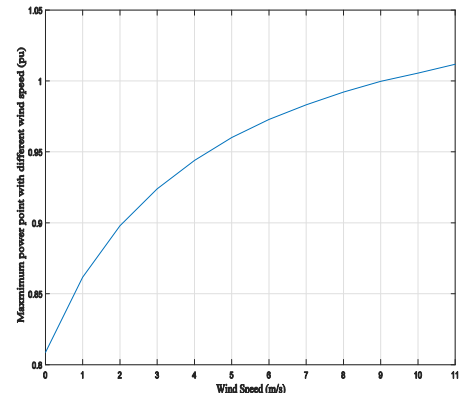

b.

Fig. 11. a. Changing value of wind speed changes the value of PV power conversion; $b$. increasing wind speed increase the maximum power point as $\ln x$.

Two environmental, ambient temperature and irradiance are changing same time and their effect on PV power conversions is shown in the Fig. 12.

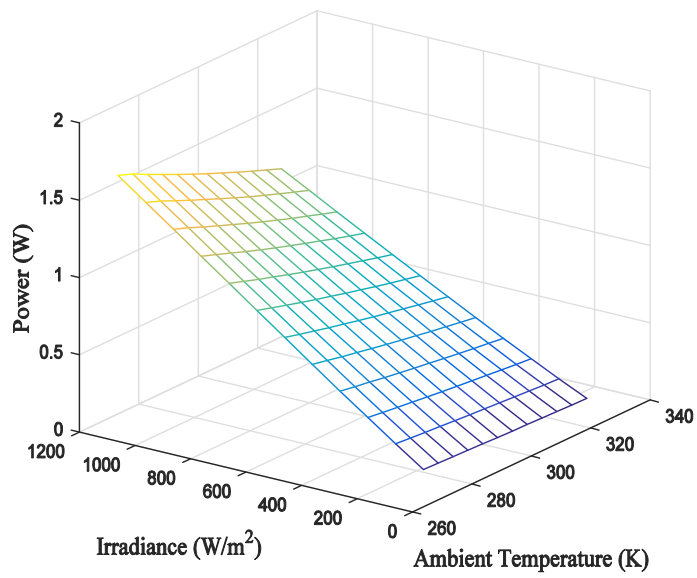

Fig. 12. PV power with changing irradiance and ambient temperature.

Two environmental, wind speed and ambient temperature are changing at the same time and their effect on PV power conversions is shown in Fig. 13. 


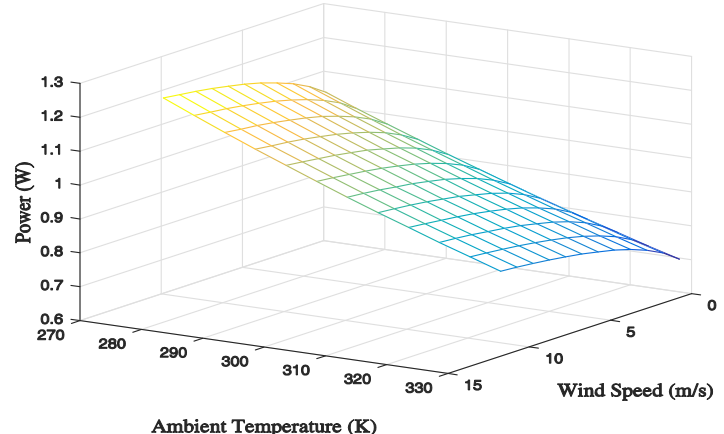

Fig. 13. PV power with changing ambient temperature and wind speed.

Two environmental, wind speed and irradiance are changing at the same time and their effect on PV power conversions is shown in Fig. 14.

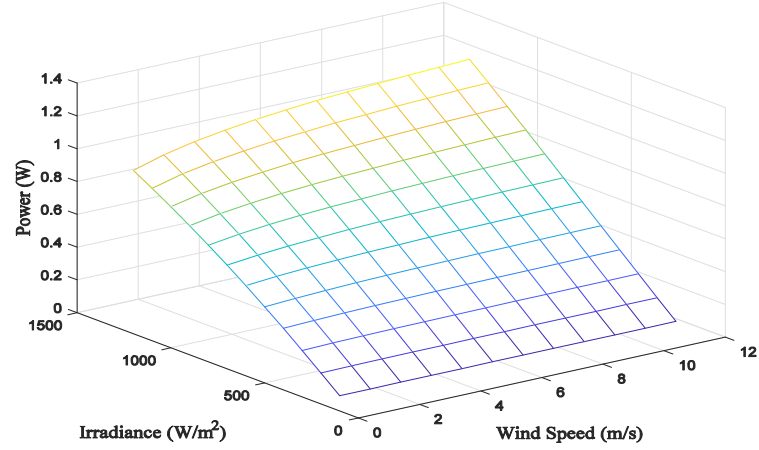

Fig. 14. PV power with changing wind speed and irradiance.

In the references [28], [29] and [30] support the results of this this section.

\subsection{Case study 3}

Table 2. shows that the increasing load values are decreasing the maximum power point of specific PV panel. It is important to get an optimal load for a specific PV panel. It shows that the experiment that the current at maximum power $\left(I_{m p}\right)$ and voltage at maximum power $\left(V_{m p}\right)$ is changing. The value of load changing also change the MPP. In the experiment, five different values of resistances are used to get the output from a specific PV panel in actual environmental state. Due to variation of load the PV power conversion rate become oscillatory. 


\subsection{Case study 4}

Shadow of different obstacles over a PV panel is simulated through Simulink model. In the real life scenario, different things create impediment for sunlight to reach the surface of PV panel. There are different types of obstacles named as shadow, dust, physical damage on PV panel etc. Due to obstacles over PV surface the P-V curve gets multiple picks that introduce local maxima and it becomes difficult to get the exact maximum power point (MPP).

Table 2. Different additive load resistance with respective maximum power.

\begin{tabular}{|c|c|c|c|}
\hline Resistance & $V_{o c}$ & $I_{s c}$ & $P_{\max }$ \\
\hline $100 \Omega$ & $5.0909 \mathrm{~V}$ & $0.0055 \mathrm{~A}$ & $0.0281 \mathrm{~W}$ \\
\hline $220 \Omega$ & $5.0959 \mathrm{~V}$ & $0.0057 \mathrm{~A}$ & $0.0275 \mathrm{~W}$ \\
\hline $560 \Omega$ & $5.1214 \mathrm{~V}$ & $0.0046 \mathrm{~A}$ & $0.0204 \mathrm{~W}$ \\
\hline $1.5 \mathrm{k} \Omega$ & $5.1048 \mathrm{~V}$ & $0.0029 \mathrm{~A}$ & $0.0149 \mathrm{~W}$ \\
\hline $4.7 \mathrm{k} \Omega$ & $5.1188 \mathrm{~V}$ & $0.0010 \mathrm{~A}$ & $0.0053 \mathrm{~W}$ \\
\hline
\end{tabular}

\subsubsection{Time-dependent obstacle}

Time-dependent obstacles are changing their shape with time over the PV surface. It is not permanent type but introduce local maxima due to shadow. They change the value of irradiance and due to this variation the PV power conversion rate also change. These types of obstacles are as; a sudden cloud, a flying bird over the PV etc. Time-dependent obstacles go over the panel surface and don't stay for long time over it [36]. Fig.15. shows a); the I-V curve against time, under rapid changing obstacles, b); P-V curve against time under rapid changing obstacles.

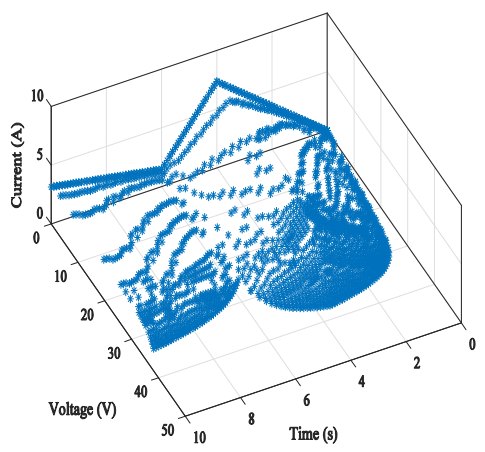

a.

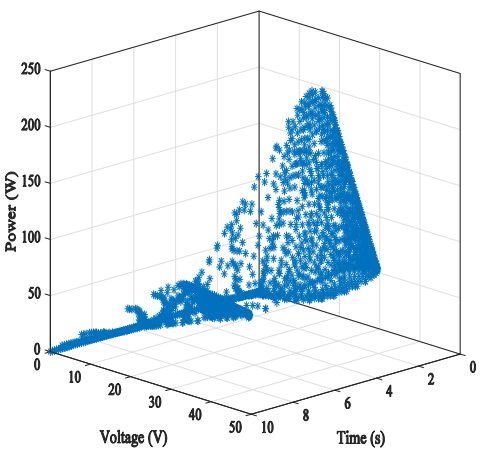

b.

Fig. 15. a. I-V curve with time under rapid changing obstacles; b. P-V curve with time under rapid changing obstacles. 


\subsubsection{Time-independent obstacle}

Time-independent obstacle is a type of permanent damage of PV panel or it may have to solve the problem manually. These types are as; few cells of PV panel are damaged, thick layer of dust, bird droppings etc. These types of problems have to solve manually. Fig. 16 shows a); the I-V curve which have 54 cells under time-independent obstacle and b); P-V curve which have 54 cells under time-independent obstacle condition.

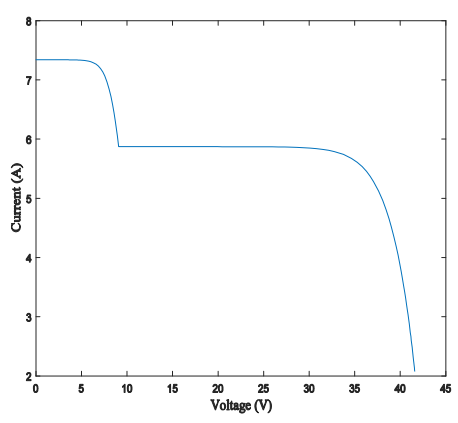

a.

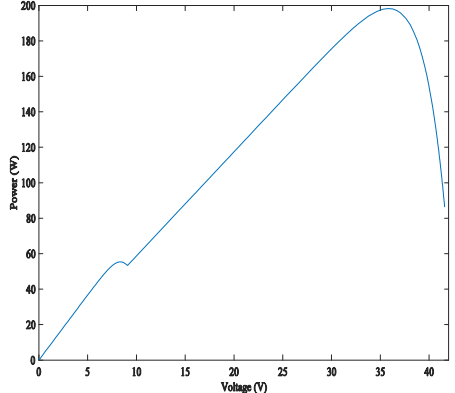

b.

Fig. 16. a. I-V curve having 54 cells under time-independent obstacle; b. P-V curve with 54 cells under time-independent obstacle condition.

\section{Conclusion and Future Work}

For developing sustainable environment and to help the world for reducing the greenhouse gases(GHG) the Paris Agreement took important decision to save the world. To implement and fulfill the vision, making energy sources clean is needed. People around the world is giving emphasis on the Renewable energy as it is a source of clean energy that can help to improve quality of the Ozone layer [37].

The simulation is done to identify the sensitivity of internal and environmental parameters through error function [1], [2], [34], [35]; Environmental variables, named irradiance, ambient temperature and wind speed variation influence on PV power conversion rate is clearly identified that is possible to include in prediction model [38], [39]; Non-constant load influence on the PV panel is identified through the experiment is done [1]; Time-dependent and time-independent obstacles are categorized to identify different types of fault in PV panel, these are important for fault identification in real working ground of PV plant [3], [36].

For future direction of this work is followed as, making experimental workout in laboratory and real environmental condition using different types of PV panels for getting their specific information to model more precise PV system that permitting to integrate with smart grid. Also developing database based on different types of obstacles of PV targeting to classify faults. It improves the system's performance. 


\section{References}

1. Rashel MR: Modeling photovoltaic panels under variable internal and environmental conditions with non-constant load. PhD Thesis, Universidade de Évora (2018)

2. Rashel MR, Rifath J, Gonçalves T, Tlemçani M, Melicio R: Sensitivity analysis through error function of Crystalline-Si photovoltaic cell model integrated in a smart grid. International Journal of Renewable Energy Research 7(4), 1926-1933 (2017)

3. Rashel MR, Albino A, Rifath J, Gonçalves T, Tlemcani M: Matlab simulink modeling of photovoltaic cells for understanding shadow effect. Proc. IEEE International Conference on Renewable Energy Research and Applications 747-750 (2016)

4. Clean Energy Reviews. URL: https://www.cleanenergyreviews.info/blog/best-quality-solarpanels-manufacturers. Accessed: 12.10 (2018)

5. Alte Store. URL: https://www.altestore.com/howto/solar-insolation-map-world-a43/. Accessed: 07.09 (2017)

6. Chen CJ: Physics of Solar Energy, John Wiley \& Sons, Inc (2011)

7. Batista NC, Melicio R, Mendes VMF: Services enabler architecture for smart grid and smart living services providers under industry 4.0. Energy and Buildings 141, 16-27 (2017)

8. Batista NC, Melicio R, Matias JCO, Catalão JPS: Zigbee standard in the creation of wireless networks for advanced metering infrastructures. Proc. 16th IEEE Melecon 220-223 (2012)

9. Ensslen A, Gnann T, Jochem P, Plotz P, Dustchke E, Fichtner W: Can product service systems support electric vehicle adoption?. Transportation Research Part A, 1-17 (2018)

10. Shaukat N, et al.: A survey on electric vehicle transportation within smart grid system. Renewable and Sustainable Energy Reviews 81, 1329-1349 (2018)

11. Paris Climate Change Conference: The global standard of globalization is not limited to the limitations of the system, XXI $2^{\circ} \mathrm{C}(2015)$

12. Bozkurt I: Energy resources and their effects on environment. WSEAS Transactions on Environment and Development 6(5) 327-334 (2010)

13. Omer AM: Energy and environment: applications and sustainable development. British Journal of Environment \& Climate Change 1(4), 118-158 (2011)

14. Mitoula R, Abeliotis K, Vamvakari M, Gratsani A: Sustainable regional development through the use of photovoltaic (PV) systems: the case of the Thessaly region. Proc. World renewable energy congress, 8-13 (2011)

15. Phuangpornpitaka N, Tia S: Opportunities and challenges of integrating renewable energy in smart grid system. Energy Procedia 34, 282-290 (2013)

16. Mekkaoui A, Laouer M, Mimoun Y: Modeling and simulation for smart grid integration of solar/wind energy. Leonardo Journal of Sciences 30, 31-46 (2017)

17. Shafiullah GM, Amanullah MTO, Ali ABMS, Wolfs P: Smart grid for a sustainable future. Scientific Research, 23-34 (2013)

18. Fialho LAP, Melicio R, Mendes VMF, Viana S, Rodrigues C, Estanqueiro A: A simulation of integrated photovoltaic conversion into electric grid. Solar Energy 110, 578-594 (2014)

19. Fialho LAP, Melicio R, Mendes VMF, Rodrigues L, Viana S, Estanqueiro A: Simulation of a-Si PV system linked to the grid by DC-DC boost and two-level converter. Proc. 16th International Power Electronics and Motion Control Conference and Exposition, 934-938 (2014)

20. Fialho LAP, Melicio R, Mendes VMF, Pereira MIC: Simulation of a-Si PV system linked to the grid by DC boost and three-level inverter under cloud scope. Technological Innovation for Cloud-Based Engineering Systems, Springer 423-430 (2015)

21. Fialho LAP, Melicio R, Mendes VMF, Estanqueiro A: Simulation of a-Si PV system grid connected by boost and inverter. International Journal of Renewable Energy Research 5(2), 443-451(2015)

22. Fialho LAP, Melicio R, Mendes VMF: Poly-Si PV system grid connected and fuzzy controlled. Proc. 16th IEEE International Conference on Computer as a Tool 1-6 (2015) 
23. Fialho LAP, Melicio R, Mendes VMF, Estanqueiro A, Pereira MIC: PV systems linked to the grid: parameter identification with a heuristic procedure. Sustainable Energy Technologies and Assessments 10, 29-39 (2015)

24. Tayyan AAE: PV system behavior based on datasheet. Journal of Electron Devices 9, 335$341(2011)$

25. Tayyan AAE: A simple method to extract the parameters of the single-diode model of a PV system. Turkish Journal of Physics 37, 121-131 (2013)

26. Aoun N, Chenni R, Nahman B, Bouchouicha K: Evaluation and validation of equivalent fiveParameter model performance for photovoltaic panels using only reference data. Energy and Power Engineering 6(9), 235-245 (2014)

27. Gokmen N, Hu W, Hou P, Chen Z, Sera D, Spataru S: Investigation of wind speed cooling effect on PV panels in windy locations. Renewable Energy 90, 283-290 (2016)

28. Dubey S, Sarvaiya JN, Seshadri B: Temperature dependent photovoltaic (PV) efficiency and its effect on PV production in the world: a review. Energy Procedia 33, 311-321 (2013)

29. Bhattacharya T, Chakraborty AK, Pal K: Effects of ambient temperature and wind speed on performance of monocrystalline solar photovoltaic module in Tripura, India. Journal of Solar Energy 2014, 1-5 (2014)

30. Zerhouni ZF, Zerhouni MH, Zegrar M, Benmessaoud MT, Stambouli AB, Midoun A: Proposed methods to increase the output efficiency of a photovoltaic (PV) system. Acta Polytechnica Hungarica 7(2), 55-70, (2010)

31. Mohamed AO, Hasan A: Effect of dust accumulation on performance of photovoltaic solar modules in Sahara environment. Journal of Basic and Applied Scientific Research 2(11), 11030-11036 (2012)

32. Piazza MCD, Vitale G: Photovoltaic field emulation including dynamic and partial shadow conditions. Applied Energy 87, 814-823 (2010)

33. Wang J, Gong H, Zou Z: Modeling of dust deposition affecting transmittance of PV modules. Journal of Clean Energy Technologies 5(3) (2017)

34. Rashel MR, Gonçalves T, Tlemçani M, Melicio R: Photovoltaic cell performance analysis under different ambient temperature and wind speed for sustainable energy. Vietnam Journal of Science, 3(1), 1-16 (2017)

35. Rashel MR, Albino A, Gonçalves T, Tlemçani M: Sensitivity analysis of environmental and internal parameters of a photovoltaic cell. Proc. Energy for Sustainability International Conference - Designing Cities \& Communities for the Future, Madeira (2017)

36. Rashel MR, Ahmed T, Gonçalves T, Tlemcani M, Melicio R: Analysis of different types of obstacles for PV panel. Eradication Poverty through Energy Innovation Workshop, Arizona State University (2018)

37. International Energy Agency: Energy and Climate Change (2015)

38. Rashel MR, Ahmed T, Goncalves T, Tlemcani M, Melicio R: Analysis of environmental parameters sensitivity to improve modeling of a c-Si panel. Sensor Letters, 16(3), 176-181 (2018)

39. Rashel MR, Albino A, Gonçalves T, Tlemçani M: Analyzing ambient temperature and wind speed effect on the photovoltaic cell. Workshop on Earth Sciences, University of Évora (2016) 